\title{
Anomalies of Arch of Aorta and Its Branches - Computed Tomography Angiography Study.
}

\author{
G.N. Charitha ${ }^{1}$, L. Vasanthi ${ }^{2}$, K. Srinidhi ${ }^{3}$ \\ ${ }^{1}$ Assistant professor, Department of Anatomy, Government Medical College (RIMS), Kadapa, Andhra Pradesh, India, ${ }^{2}$ Assistant professor, Department of \\ Anatomy, Guntur Medical College, Guntur, Andhra Pradesh, India, ${ }^{3}$ Internee, NRI Medical College, Chinnakakani, Andhra Pradesh, India.
}

\section{Abstract}

Introduction: The arch of aorta is a curved structure between the ascending aorta and the descending aorta.Three branches arise from the superior aspect of the arch- Brachiocephalic trunk, Left common carotid artery and Left subclavian artery. The aortic arch and its branches are well known for their anomalies which are important causes of cardio-vascular morbidity and mortality. The present study contribute for awareness and alertness regarding their incidence and prevalence for radiologists, cardiologists and endo-thoracic surgeons and to prevent complications during therapeutic procedures. Subjects and Methods: 500 CTA images were studied retrospectively from the patients who underwent chest and neck CTA for different reasons. Results: Out of 500 patients 474 (94.8\%) patients had the classical branching pattern with left sided aorta. Six types of anomalies of the aortic arch and its branches were found in 26 (5.2\%) patients. The most common anatomical variant was a common trunk for Brachiocephalic trunk and Left Common Carotid artery (bovine arch) found in 9 (1.8\%) patients. In five (1\%) patients, Left Vertebral Artery arises directly from the arch of aorta between left common carotid artery and left subclavian artery. Five (1\%) patients had Right sided arch of aorta. Aberrant Right subclavian artery was found in four $(0.8 \%)$ patients. Double arch in $2(0.4 \%)$ cases and in one $(0.2 \%)$ patient, we observed five branches arising directly from the arch, they are Right Common Carotid artery, Left Common Carotid artery, Left Vertebral artery, Left Subclavian artery and Aberrant Right Subclavian artery. Conclusion: With the ever increasing day to day advancements in complex endovascular interventions for the aorta and other great vessels of head and neck regions, early identification of aortic arch variant anatomy is of clinical significance to the radiologists and endovascular surgeons.

Keywords: Aortic Arch direction, variant branching pattern, computed tomography angiography (CTA).

Corresponding Author: Dr. L. Vasanthi, Assistant professor, Department of Anatomy, Guntur Medical College, Guntur, Andhra Pradesh, India.

Received: May 2019

Accepted: June 2019

\section{Introduction}

The arch of aorta or the transverse aortic arch, is a structure of bow-like or curved out-line portion between the ascending aorta and the descending aorta, being situated in the superior mediastinum behind the manubrium sterni. Three branches arise from the superior aspect of the archBrachiocephalic trunk, Left common carotid artery and Left subclavian artery. This is found in $65-80 \%$ of the population. ${ }^{[1,2]}$

The aortic arch and its branches are well known for their variations in the thoracic region. These anomalies are due to the variations in the extent of fusion process and absorption of some of the aortic arches into the aortic sac.

Aortic diseases are one of the important causes of cardiovascular morbidity and mortality. Generally they are asymptomatic and often cannot be detected on physical examination. However, they frequently present as life threatening situations. The proximal segment of the aortic arch branches are more prone for Atherosclerosis and anomalies of these vessels causes changes in the cerebrohemodynamics resulting in cerebrovascular accidents. ${ }^{[3]}$

Momma et.al. noted the association of certain aortic arch anomalies with chromosomal disorder $22 \mathrm{q} 11$ deletion. ${ }^{[4]}$ Abnormal vascular pattern of the arch of aorta sometimes present as a complete vascular ring around trachea and oesophagus causing clinical symptoms like dyspnea, dysphagia.

An unrecognized variation of the aortic arch vascular anatomy leads to serious ischaemic complications during diagnostic and surgical interventions. Therefore, there is a need for the increased awareness and alertness regarding their incidence and prevalence for radiologists, cardiologists and endo-thoracic surgeons. The advanced non-invasive diagnostic modalities helps in the early identification of aortic arch anomalies and to prevent complications during therapeutic procedures.

The aim of the present study was to determine the incidence of normal anatomy of the aortic arch and its branches and the percentage of the variations in the aortic arch direction 
and its branching pattern by Computed Tomography Angiography.

\section{Subjects and Methods}

The present study was done on the aortic arch and its branching pattern on the individuals referred to radiology department for the evaluation of a variety of non-vascular clinical problems, and to evaluate chest and neck masses by using a non-invasive imaging modality, Computed Tomography Angiography.

A total of 500 post-contrast enhanced CTA images were retrospectively collected and studied from Ramesh Hospitals, Guntur \& Global Hospitals, Vijayawada over a period of 3 years (2016-2018). All the MDCT scans were obtained using PHILIPS, BRILLIANCE 64 Slice helical CT scanner, and all the images were analysed using Philips Dicom view.

\section{Results}

A total of 500 patients CTA images were retrospectively studied for the incidence of variations in the direction of the aortic arch \& its branching pattern. Out of 500, 474 (94.8\%) patients had normal classical branching pattern with left sided aortic arch and 26 patients (5.2\%) had variant aortic arch anatomy.

Of these 26 patients, $9(1.8 \%)$ had common trunk for BCT \& LCCA (bovine arch) [Figure 1]; 5 (1\%) had Left Vertebral Artery arising directly from the aortic arch [Figure 2]; another $5(1 \%)$ patients have Right sided aortic arch [Figure 3]; Aberrant Right subclavian artery was found in $4(0.8 \%)$ cases [Figure 4]; double aortic arch in $2(0.4 \%)$ cases [Figure 5] and in 1 (0.2\%)case, five vessels arise from the aortic arch ie., Rt. CCA, Lt. CCA, Lt. Vertebral Artery, Lt. Subclavian artery \& Aberrant Rt. Subclavian artery fig.6

\begin{tabular}{|l|l|l|}
\hline Variations & Total & Percentage \\
\hline $\begin{array}{l}\text { Bovine arch (Common Trunk for } \\
\text { BCT \& LCCA) }\end{array}$ & 9 & $1.8 \%$ \\
\hline $\begin{array}{l}\text { Left Vertebral Artery directly } \\
\text { arising from the arch }\end{array}$ & 5 & $1 \%$ \\
\hline Rt. Sided Aortic arch & 5 & $1 \%$ \\
\hline Aberrant Rt. Subclavian artery & 4 & $0.8 \%$ \\
\hline Double Aortic arch & 2 & $0.4 \%$ \\
\hline $\begin{array}{l}\text { Five vessels from the } \\
\text { arch...Rt.CCA, Lt. CCA, Lt.VA, } \\
\text { Lt. SCA, Aberrant Rt. SCA }\end{array}$ & & \\
\hline Total Variations & 26 & $5.2 \%$ \\
\hline
\end{tabular}

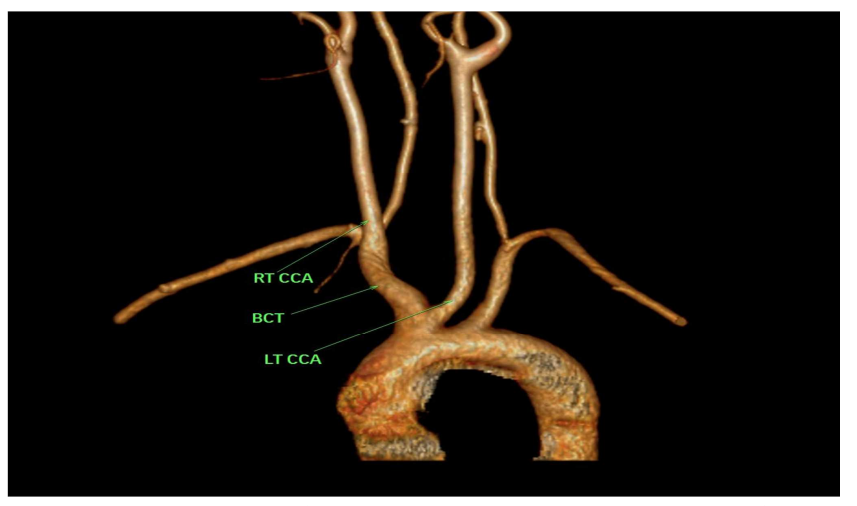

Figure 1: Bovine arch (Common Trunk for BCT \& LCCA)

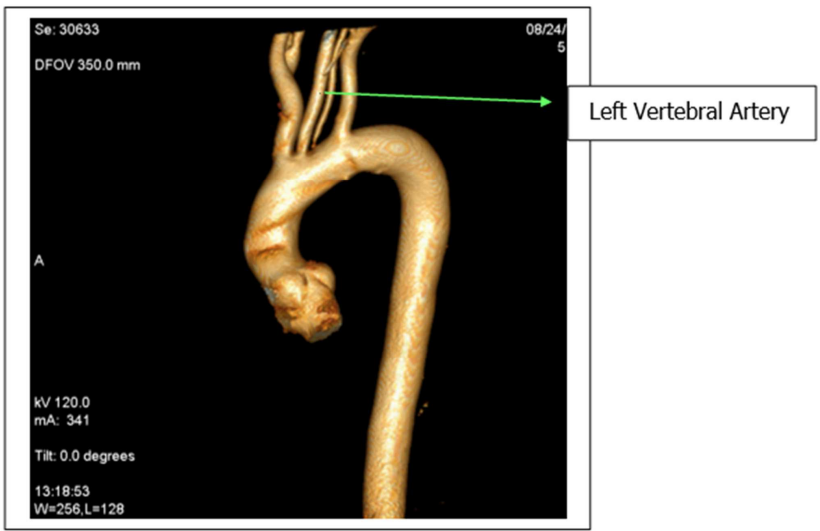

Figure 2: Left Vertebral Artery arising directly from the aortic arch

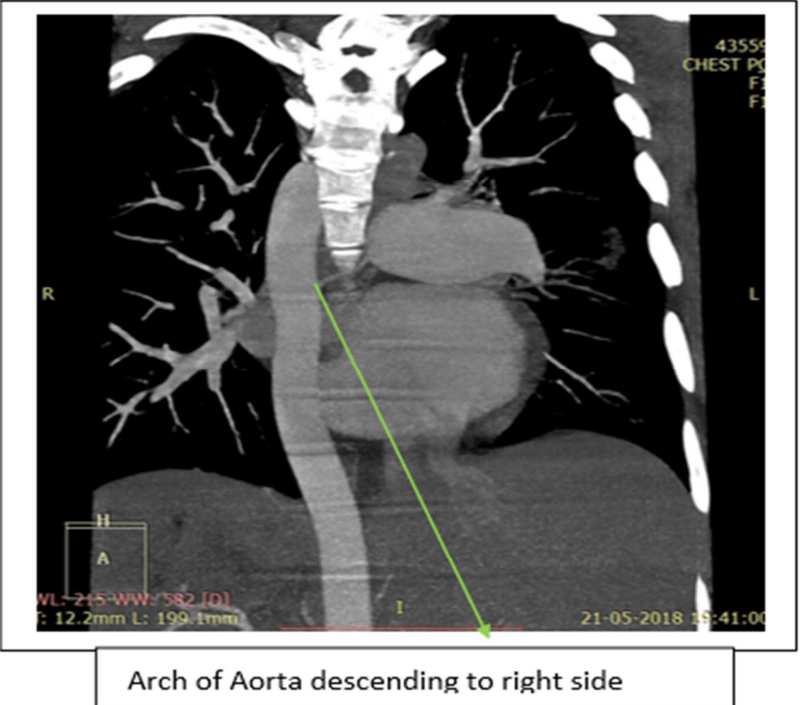

Figure 3: Rt. Sided Aortic arch

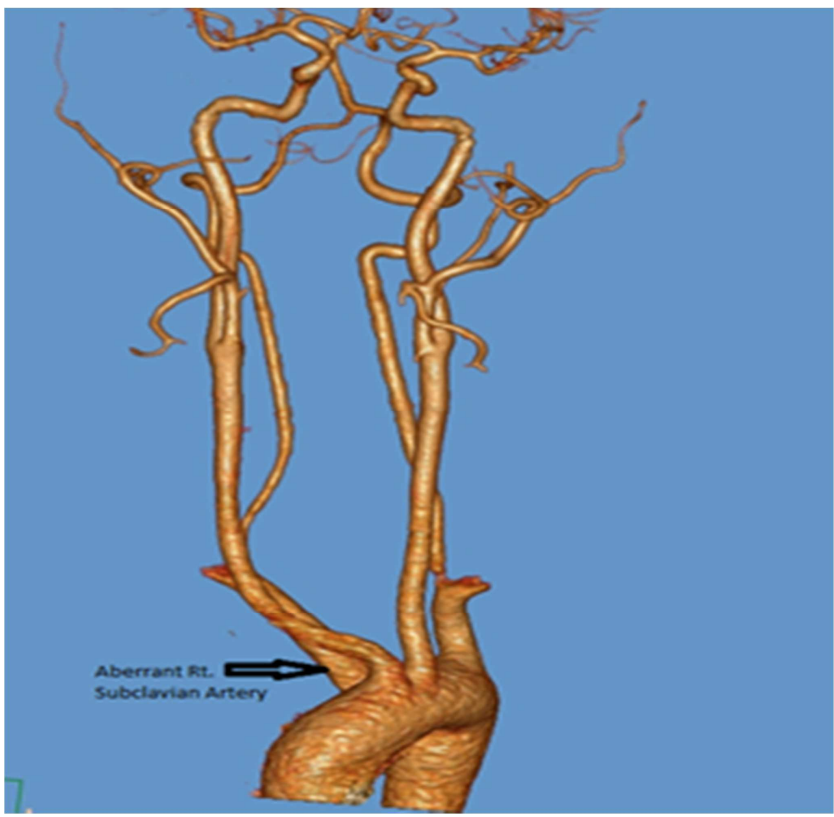

Figure 4: Aberrant Rt. Subclavian artery 

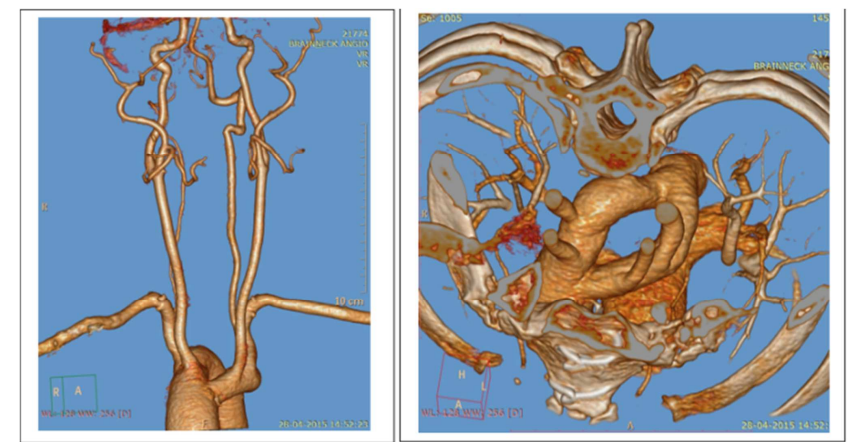

Figure 5: Double Aortic arch
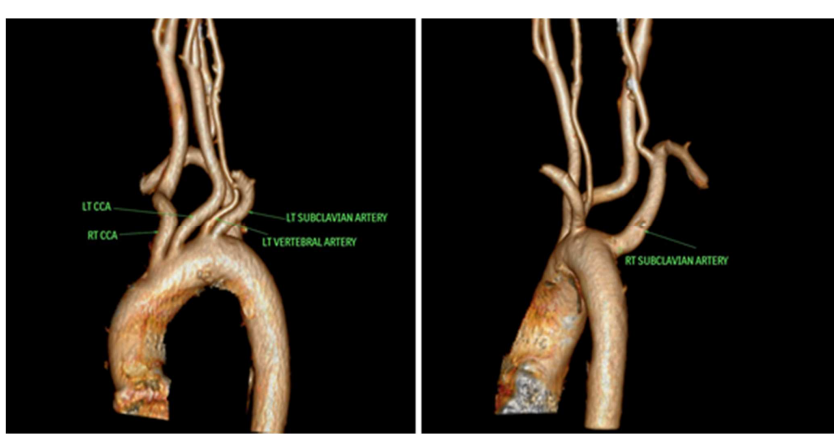

Figure 6: Five vessels from the arch...Rt.CCA, Lt. CCA, Lt.VA, Lt. SCA, Aberrant Rt. SCA

\section{Discussion}

Cardiovascular diseases are one of the main causes of death world- wide in developing countries than developed countries. As they underwent rapid industrialization, urbanization, economic development \& market globalization over last few decades which leads to the improvement in standards of living with a detrimental shift towards inappropriate dietary pattern \& a reduction in physical activities. All these cause unnecessary \& inappropriate stresses affecting various body functions and organ damage. Aortic diseases are one of the important causes of cardiovascular morbidity and mortality. ${ }^{[5]}$

Development of a human being from a single cell happens through a complex process in the intra-uterine period. The embryonic development of the arch of aorta begins during 4 th to 8th week of intra- uterine life. The aortic arch develops from the aortic sac, left fourth aortic arch \& part of the left dorsal aorta. ${ }^{[6]}$

Any change in its normal developmental period due to any cause results in anatomical variations either in the aortic arch direction or its branching pattern. Variant anatomy of the aortic arch and its branches has clinical significance in the interventional procedures of the neck \& thoracic regions. In the present study, classical three branch pattern with left sided aorta was observed in $94.8 \%$ cases, similar to the studies done by Budhiraja Virendra $(95 \%),{ }^{[7]}$ Martia L.Nelson Chad D Sparks (94.3\%) and in 5.2\% cases, 6 types of variations in the aortic arch \& its branches were observed. $^{[8]}$

1. Common trunk for BCT \& LCCA (Bovine Arch):- This is a common variation with an incidence of $10-22 \%$ as given in the literature. Normally during development aortic sac bifurcates into right and left limbs, where left limb forms the part of arch by intervening between the origins of BCT \& LCCA. If this aortic sac fails to bifurcate, BCT \& LCCA both will connect to the aortic sac directly resulting in common trunk for BCT \& LCCA. Martia L.Nelson, Chad D Sparks et.al reported this variation in $1.03 \%$ cases, ${ }^{[8]}$ in $3.4 \%$ cases according to Satyapal K.S.Singaram et.al, whereas in the present study it was found in 9 cases $(1.8 \%) .{ }^{[9]}$ Recent studies reported the association of bovine arch with the development of thoracic aneurysms and an increased risk of torsion and deceleration injuries due to two fixation points instead of three. ${ }^{[10,11]}$

2. Left Vertebral Artery:- Left vertebral artery arising directly from arch of aorta between LCCA \& Lt. Subclavian artery is not uncommon with a prevalence range between 2.4- $8 \%$ as reported in the literature.

Embryologically, left vertebral artery develops from the process of longitudinal anastomosis and obliteration of the horizontal parts of the cervical intersegmental arteries. According to Satti et. al., it is due to the persistence of the dorsal intersegmental arteries more cranial than the seventh intersegmental artery which is the typical site of anastomosis. ${ }^{[12]}$ Persistent sixth cervical intersegmental artery and the failure of the disappearance of segment of dorsal aorta results in the left vertebral artery arising from the aortic arch as reported by Soubhagya R Nayak et. al. ${ }^{[13]}$ Natsis et. al., have reported this variation in $0.79 \%$ cases, ${ }^{[14]}$ in $1.6 \%$ cases according to Satyapal K.S.Singaram and Soubhagya R Nayak et. al, ${ }^{[9,13]}$ in the current study, it was observed in 5 cases $(1 \%)$. Komiyama $\mathrm{M}$ et.al. reported the higher incidence of vertebral artery dissection with this anomaly and even cause variant of subclavian steal syndrome with resultant brain ischemia according to Kizilkilic O, et al. ${ }^{[15,16]}$

3. Right sided aortic arch:- The right sided aortic arch is an uncommon anomaly occurring in $<0.1 \%$ of the population. It results from the persistence of entire fourth arch on the right side \& the involution of the distal part of the corresponding arch on the left side. Rea $\mathrm{G}$ et. al, reported this variation in $0.5 \%$ in his study, ${ }^{[17]}$ it is $0.4 \%$ according to Nellaiappan Chellaiah, ${ }^{[18]}$ while some of the authors presented as case reports. In the current study it was found in 5 cases (1\%) of the study population.

4. Aberrant Right Subclavian artery:- The emergence of Aberrant Right Subclavian artery as the last branch of aortic arch is between $0.13 \%$ to $25 \%$ as reported in the literature. When the right fourth aortic arch degenerates, the right seventh intersegmental artery \& the distal part of the right dorsal aorta continues as Aberrant Right Subclavian artery from the aortic arch. It courses behind the oesophagus or between trachea \& oesophagus or sometimes infront of the trachea. Most of the cases are asymptomatic, while Retro-oesophageal course causes dysphagia, a clinical condition called Arteria lusoria. Moss \& Adams reported its incidence in $0.9 \%,{ }^{[19]}$ Apichitruengdej \& Chentanez found in $0.89 \%,{ }^{[20]}$ while it was observed in 4 cases $(0.8 \%)$ in the present study.

5. Double Aortic arch:- It is a rare anomaly resulting from the persistence of both fourth aortic arches and both 
dorsal aortae. This is the most common form of symptomatic complete vascular ring, that compresses trachea \& oesophagus causing stridor, dysphagia, recurrent respiratory infections in the first six months of life. ${ }^{[21]}$ Nellaiappan Chellaiah observed in $0.2 \%$, Pasaoglu Lale et. al. observed in $0.1 \%$ cases. $^{[22]}$ In the current study it was observed in 2 cases $(0.4 \%)$.

6. A very rare anomaly was observed in 1 case $(0.2 \%)$ where five branches arise directly from the arch of aorta, Right Common Carotid artery, Left Common Carotid artery, Left Vertebral artery, Left Subclavian artery and Aberrant Right Subclavian artery as the last branch.

\section{Conclusion}

Anatomical variations of the aortic arch and its branches are frequently observed, mostly as an incidental finding during routine diagnostic procedures. Detailed knowledge of these anomalies is of great significance in cases of vascular diseases such as Aneurysms or arterio-venous malformations prior to diagnostic and therapeutic interventions in order to avoid complications and to have a better outcome.

\section{Acknowledgement}

We would like to express our sincere thanks to Dr. V. N. Varaprasad, Radiologist, Global Hospitals and Dr. Supraja Chegireddy, Radiologist, Ramesh Hospitals, Guntur for their kind support and co-operation in collection of Computed Tomography Angiography images that helped a lot in completing this work.

The authors have no conflict of interest to report.

\section{References}

1. Susan Standring (2008), Gray's Anatomy. The anatomical basis of clinical practice, 40th Edition, chapter 53: 913-914; chapter 56: 984-985.

2. Mligiliche NL, Isaac ND. A three branches aorticarch variant with a bicarotid trunk and a retro-esophageal right subclavian artery. Int J Anat Variat2009;2:11-1.

3. Shiva Kumar GL, Pamidi N, Somayaji SN, Nayak S, Vollala VR, Anomalous branching pattern of the aortic arch and its clinical applications Singapore Med J. 201;51(11):182-3.

4. Momma K, Matsuoka R, Takao A. Aortic arch anomalies which are associated with the chromosome 22q11 deletion (CATCH 22). Pediatr Cardiol. 1999;20:97-102.

5. Shanthi Mendis, Pekka Puska and Bo Norrving (2011), Global Atlas on cardiovascular disease prevention and control: World Health Organization, Geneva, in collaboration with the World Heart Federation and the World Stroke Organization.

6. Keith L. Moore and T.V.N. Persaud (2009), Clinically Oriented
Embryology, The Developing Human, 8th Edition, chapter 13: 291-292; 317-319.

7. Virendra Budhiraja, Rakhi Rastogi, Vaishali Jain, Vishal Bankwar, and Shiv Raghuwanshi, "Anatomical Variations in the Branching Pattern of Human Aortic Arch: A Cadaveric Study from Central India," ISRN Anatomy, vol. 2013, Article ID 828969, 5 pages, 2013.

8. M. L. Nelson and C. D. Sparks, "Unusual aortic arch variation: distal origin of common carotid arteries," Clinical Anatomy, vol. 14, no. 1, pp. 62-65, 2001.

9. K. S. Satyapal, S. Singaram, P. Partab, J. M. Kalideen, and J. V. Robbs, "Aortic arch branch variations-case report and arteriographic analysis," South African Journal of Surgery, vol. 41, no. 2, pp. 48-50, 2003.

10. Moise MA, Hsu V, Braslow B, etal. Innominate artery transection in the setting of a bovine arch. J Thorac Cardiovasc Surg 2004;128:632-4.

11. Malone CD, Urbania TH, Crook SE, etal. Bovine aortic arch: A novel association with thoracic aortic dilation. Clin Radiol 2012;67:28-31.

12. Satti S R, Cerniglia C A, Koenisberg R A (2007), Cervical vertebral artery variations: an anatomic study: AJNR Am J Neuroradiol; 28 (5): 976-80.

13. S. R. Nayak, M. M. Pai, L. V. Prabhu, S. D'Costa, and P. Shetty, "Anatomical organization of aortic arch variations in the India: embryological basis and review," Jornal Vascular Brasileiro, vol. 5, no. 2, pp. 95-100, 2006.

14. K. I. Natsis, I. A. Tsitouridis, M. V. Didagelos, A. A. Fillipidis, K. G. Vlasis, and P. D. Tsikaras, "Anatomical variations in the branches of the human aortic arch in 633 angiographies: clinical significance and literature review," Surgical and Radiologic Anatomy, vol. 31, no. 5, pp. 319-323, 2009

15. Komiyama M, Morikawa T, Nakajima H et al (2001), High incidence of arterial dissection associated with left vertebral artery of aortic origin: Neurol Med Chir (Tokyo); 41:8-11

16. Kizilkilic O, Oguzkurt L, Tercan F et al (2004), Subclavian steal syndrome from the ipsilateral vertebral artery: AJNR Am J Neuroradiol; 25: 1089-91.

17. Rea G, Valente T, Iaselli F, Urraro F, Izzo A, Sica G, Muto M, Scaglione M, Muto M, Cappabianca S, Rotondo A. Multi-detector computed tomography in the evaluation of variants and anomalies of aortic arch and its branching pattern. Ital $\mathrm{J}$ Anat Embryol. 2014;119(3):180-92.

18. Nellaiappan Chelliah. Retrospective analytical five months study of aortic arch abnormalities. Int Jour Res Med Sci 2016;4:385-9.

19. Moss and Adams, Paul M. Weinberg. Lippincotts williams \& wilkins. Vol. II; 707-735.

20. Apichitruengdej U, Chentanez V. Anomalies of thesubclavian artery and superior vena cava: Aberrantright subclavian artery and double superior venacavae. Chula Med J. 1995; 39:337-49.

21. Thankavel PP, Brown PS, Lemler MS. Left- Dominant Double Aortic Arch in Critical Pulmonary Stenosis and Ventricular Septal Defect. Pediatr Cardiol 2012; 33:1469-71.

22. Pasaoglu Lale, Ugur Toprak, Gökhan Yagız, Tunca Kaya, and Sadık Ahmet Uyanık, "Variations in the Branching Pattern of the Aortic Arch Detected with Computerized Tomography Angiography," Advances in Radiology, vol. 2014, Article ID 969728, 6 pages, 2014.

Copyright: () the author(s), publisher. Academia Anatomica International is an Official Publication of "Society for Health Care \& Research Development". It is an open-access article distributed under the terms of the Creative Commons Attribution Non-Commercial License, which permits unrestricted non-commercial use, distribution, and reproduction in any medium, provided the original work is properly cited.

How to cite this article: Charitha GN, Vasanthi L, Srinidhi K. Anomalies of Arch of Aorta and Its Branches - Computed Tomography Angiography Study. Acad. Anat. Int. 2019;5(1):112-115.

DOI: dx.doi.org/10.21276/aanat.2019.5.1.27

Source of Support: Nil, Conflict of Interest: None declared. 